\title{
Possibilities and limitations of antidepressant use to correct depressive and negative symptoms in schizophrenia
} Maxim A. Novitsky ${ }^{1 *}$, Avinash De Sousa ${ }^{2,3}$, Azat R. Asadullin ${ }^{1,4}$, Oksana A. Gavrilyuk ${ }^{5}$, Artem V. Petrov ${ }^{5}$, Regina F. Nasyrova $^{1 * 3}$

Citation: Novitsky, M.A.; De Suosa, A.; Asadullin, A.R.; Gavrilyuk, O.A.; Petrov, A.V.; Nasyrova, R.F. Possibilities and limitations of antidepressant use to correct depressive and negative symptoms in schizophrenia Personalized Psychiatry and Neurology 2021, 1 (2): 21-45.

https://doi.org/10.52667/2712-91792021-1-2-21-45

Chief Editor: Nikolaj G. Neznanov, D Med Sci, Professor

Received: 6 August 2021 Accepted: 28 September 2021 Published: 15 November 2021

Publisher's Note: V.M. Bekhterev NMRC PN stays neutral with regard to jurisdictional claims in published maps and institutional affiliations.

Copyright: $₫ 2021$ by the authors.
1 V.M. Bekhterev National Medical Research Centre for Psychiatry and Neurology; 3, Bekhterev str., 192019 , Saint-Petersburg, Russian Federation; maximnovitsky93@gmail.com (M.A.N.); nreginaf77@gmail.com (R.F.N.);

${ }^{2}$ Lokmanya Tilak Municipal Medical College, 400022, Mumbai, India; avinashdes888@gmail.com (A.D.S.);

${ }^{3}$ International Centre for Education and Research in Neuropsychiatry (ICERN), Samara State Medical University, 443079, Samara, Russia; avinashdes888@gmail.com (A.D.S.); nreginaf77@gmail.com (R.F.N.);

${ }^{4}$ Bashkir State Medical University; 3, Lenin str., 450008, Ufa, Russian Federation; droar@yandex.ru (A.R.A.);

5 The Center of Collective Usage "Molecular and Cell Technologies”, V. F. Voino-Yasenetsky Krasnoyarsk State Medical University; 1, P. Zheleznyak str., 660022, Krasnoyarsk, Russian Federation; artvpetrov@mail.ru (A.V.P.); oksana.gavrilyuk@mail.ru (O.A.G.)

*Correspondence: nreginaf77@gmail.com (R.N.F.); maximnovitsky93@gmail.com (M.A.N.); Tel.: + 7 (812) 62002-20 (R.F.N. and M.A.N.)

Abstract: The purpose of this review is to analyze approaches to the treatment of depressive and negative disorders in schizophrenia in terms of their level of efficacy and safety. Materials and Methods: A search was conducted for full-text articles published over the last 10 years in PubMed, Springer, Wiley Online Library, Taylor \& Francis Online, APA PsycInfo, CORE, Science Direct, and eLIBRARY.RU databases. Several articles published previously to this period were also included into the review due to their high scientific value. Results: Our review suggests that antidepressants (ADs) are effective medications and they can be prescribed to correct depressive disorders and negative symptoms in patients with schizophrenia when used in combination with antipsychotics (APs). However, when administering ADs and APs combinations, it is important to consider the safety profile of these combinations as well as their tolerance. Negative symptoms of schizophrenia, including those induced by a number of AP, are less amenable to correction by ADs monotherapy, which requires a long period of APs (on average - 8 weeks), which can be limited in the real life of the patient outside the hospital. Current approaches to the therapy of depressive disorders in patients suffering from schizophrenia vary from country to country. However, most of ADs used in clinical psychiatric practice are widely used in the comorbid state under consideration. Conclusion: The efficacy and safety of ADs of the different classes considered in this review depends on their mechanisms of action, duration of admission, type of APs taken, and specific clinical situation (acute depressive disorder, major depressive episode, or chronic depressive episode). Most promising in clinical practice are serotonin-norepinephrine reuptake inhibitors (SNRIs) and dual ADs. The use of tricyclic antidepressants (TCAs) is limited due to a higher risk of adverse drug reactions (ADRs). The use of most selective serotonin reuptake inhibitors (SSRIs) is limited due to the risk of aggravation of hallucinations (this risk being higher for patients with visual hallucinations, and lower for those with auditory hallucinations) and $\backslash$ or iatrogenic psychosis. These ADRs may probably occur in patients suffering from schizophrenia due to their ideal "poor metabolizer" pharmacogenetic profile, since most of the drugs considered in this review have hepatic metabolism.

Keywords: depressive disorders; depression; bipolar disorder; schizophrenia; antipsychotics; antidepressants; treatment. 


\section{Introduction}

Depressive disorders in patients with schizophrenia are the most common comorbid conditions, caused by the influence of external environmental [1], genetic [2], and epigenetic factors and their combinations. Depressive disorders worsen the course of schizophrenia, reduce the effectiveness of APs therapy, increase the risk of developing psychoses, suicidal attempts, and completed suicides [3]. Timely therapy of depressive disorders largely depends on methodological approaches to their diagnosis [4].

Thus, the relevance of the problem under consideration is beyond doubt in psychiatric practice. At the same time, approaches to the selection of ADs and their combination with the taken APs in patients with schizophrenia may be limited due to the peculiarities of the drug-drug interaction, as well as due to genetically determined changes in pharmacokinetics and pharmacodynamics. Everyone's metabolism is different. Cytochrome P450 system is a family of about 60 genes that produce enzymes that metabolize medications, including APs and ADs. Six of those enzymes metabolize about 90 percent of medications. Some patients with schizophrenia are poor metabolizers (due to the carrier ship of low functional or non-functional alleles of single nucleotide variants (ONVs) of genes encoding key enzymes of APs and ADs metabolism) $[5,6]$. The medications are broken down very slowly in poor metabolizers. These patients may experience adverse drug reactions (ADRs) at standard doses [7, 8]. Hence, the use of ADs in these patients with schizophrenia can lead to an increase in the severity of positive symptoms, the development of acute psychoses as well as other serious ADRs [9].

Although most APs of second generation (also known as atypical APs) can have antidepressant effects [10,11], in some cases, patients with schizophrenia require additional antidepressant medication. Combinations of APs and ADs for the correction of negative and positive symptoms in schizophrenia are being actively studied, but there is no single approach to the most effective and safe co-administration.

\section{Materials and Methods}

The search strategies:

- We used keywords "depressive disorders"; "depression"; "bipolar disorder"; "schizophrenia"; "antipsychotics"; "antidepressants"; "treatment", and their combinations, for the search full-text articles in PubMed, Springer, Wiley Online Library, Taylor \& Francis Online, APA PsycInfo, CORE, Science Direct, and eLIBRARY.RU databases.

- We analyzed placebo-controlled studies, cross-sectional studies, case-control studies, case studies, systematic reviews, meta-analyzes, and Cochrane reviews. Articles published from January 2011 to July 2021 were analyzed. The final date of the search was 26 July 2021.

- Analyzed data have been pre-selected from identified studies by the titles and abstracts or from the entire publication if titles and abstracts did not provide sufficient information on the type of study.

- English and Russian languages were included.

- Duplicate articles were excluded from the analysis. 
Several articles published previously to this period were also included into the review due to their high scientific value. We analyzed 37 studies in this thematic review.

\section{Results}

Table 1 shows data on ADs studied with respect to the possibility of correction of depressive and negative symptoms in patients with schizophrenia.

Table 1. Antidepressants used to correct depressive and negative symptoms in patients with schizophrenia

\begin{tabular}{|c|c|c|}
\hline Group & Drugs & References \\
\hline $\begin{array}{l}\text { Monoactive substances } \\
\text { Monoamine oxidase inhibitors (MAOIs) }\end{array}$ & $\begin{array}{c}\text { Bifemelane } \\
\text { Izocarboxazid } \\
\text { Moclobemide } \\
\text { Phenelzine } \\
\text { Tranylcypromine } \\
\text { Toloxatone }\end{array}$ & [12] \\
\hline Selective serotonin reuptake inhibitors (SSRIs) & $\begin{array}{c}\text { Citalopram } \\
\text { Fluoxetine } \\
\text { Escitalopram } \\
\text { Paroxetine } \\
\text { Sertraline } \\
\end{array}$ & [13] \\
\hline Selective norepinephrine reuptake inhibitors (SNRIs) & $\begin{array}{l}\text { Maprotiline } \\
\text { Reboxetine }\end{array}$ & {$[14]$} \\
\hline $\begin{array}{l}\text { Dual-acting substances } \\
\text { Classic and modified tricyclic antidepressants (TCAs) }\end{array}$ & $\begin{array}{l}\text { Amitriptyline } \\
\text { Clomipramine } \\
\text { Doxepin } \\
\text { Imipramine }\end{array}$ & {$[15]$} \\
\hline Serotonin and norepinephrine reuptake inhibitors (sNRIs) & $\begin{array}{l}\text { Duloxetine } \\
\text { Venlafaxine }\end{array}$ & [17] \\
\hline Norepinephrine and dopamine reuptake inhibitors (NDRIs) & $\begin{array}{c}\text { Bupropion } \\
\\
\text { Agomelatin } \\
\text { Bupropion } \\
\text { Mianserin } \\
\text { Mirtazapine } \\
\text { Nefazodone } \\
\text { Trazodone }\end{array}$ & {$[18]$} \\
\hline
\end{tabular}

\section{Monoamine oxidase inhibitors}

Monoamine oxidase inhibitors (MAOI) were one of the first developed classes of ADs. MAOIs inhibit the decay of these neurotransmitters, thereby increasing their level in the synaptic cleft and allowing them to continue to affect on effector cells (neurons), the malfunction of which is the cause of a development of depressive disorders [20, 21].

There are two types of MAO. The first one, type A (MAO-A) is mainly expressed in a placenta, intestine, and liver. The second one, type B (MAO-B) is mainly expressed in a brain, liver, and platelets. Serotonin and noradrenaline are substrates of MAO-A, while 
phenylethylamine, methylhistamine and tryptamine are substrates of MAO-B. Dopamine and tyramine are metabolized by both MAO types. The discovery of these two different $\mathrm{MAO}$ isoenzymes with different substrate selectivity and expression pattern in different tissues led to new therapeutic approaches and the development of new classes of inhibitors, including selective irreversible and reversible MAO-B inhibitors and reversible MAO-A inhibitors. Usually, MAO-A is associated with oxidative deamination of serotonin, while MAO-B catalyzes predominantly benzylamine and 2-phenethylamine. Dopamine, noradrenaline, adrenaline, tryptamine, and tyramine are associated with similar substrate MAO inhibitors: from classical to new clinical approaches of specificity for both isoenzymes. Selegiline and rasagiline are irreversible and selective MAO-B inhibitors, and safinamide is a reversible and selective MAO-A inhibitor [21].

The joint use of MAOIs with APs of various groups has been mentioned since the late 70s of the twentieth century. Thomas et al. [22] mentioned combination therapy of MAOIs with different groups of APs. If we talk about the joint use of MAOIs and SSRIs in a treatment of schizophrenia, then we should remember a high risk of the development of serotonin syndrome both in the use of therapeutic doses and in cases of overdose, up to death. [23-25].

In addition, deaths related to combined use of MAOIs including SSRIs were reported in patients treated with therapeutic doses and high doses (overdose) [26, 27]. To avoid serious ADRs, it was recommended to stop taking SSRIs at least 2 weeks before the start of MAOIs therapy, with the exception of fluoxetine, which requires a 5-week wash-out period [28].

Intake of MAOIs and atypical AD (trazodone) is considered to be safer. Trazodone has proved to be effective in the correction of sleep disorders, including treatment of insomnia caused by use of MAOIs [29-31]. However, publications on the use of MAOIs with trazodone in patients with psychotic symptoms and sleep disorders are limited [30, 31], although, in general, their joint use is considered safe and effective.

Tranylcypromine is an irreversible and non-selective MAOIs A and B type prescribed primarily to treat resistant depression. Ulrich et al. [32] has conducted a meta-analysis of an efficacy and safety of its co-use with APs as a third-line therapy in a distinct group of patients with chronic schizophrenia with a predominance of negative symptoms and the presence of depressive disorders over a limited (of 12 to 16 weeks) period of combination therapy. The meta-analysis included seven control studies of the use of tranylcypromine in combination with $\mathrm{AP}$ as well as four studies with prospective and parallel follow-up of patients who took this drug in combination with $\mathrm{AP}$, against patients who received $\mathrm{AP}$ monotherapy. The authors evaluated an effectiveness of therapy, as well as ADRs in the form of extrapyramidal syndrome and exacerbation of positive symptoms of schizophrenia in patients as a result of tranylcypromine and AP combination therapy. Despite the limited studies analyzed and heterogeneity of samples, the odds ratio (OR) in reducing the severity of negative symptoms of schizophrenia and depressive disorders was 1.558 [95\% CI 0.340 - 2.776, NS]. The main clinical limitation of the studies analyzed by the authors was the proven effect of these MAOIs on second generation APs. Important, tranylcypromine acts as a nonselective and irreversible MAOI and therefore is not recommended in different combinations (and not available in many countries).

Phenelzine is a non-selective MAOI that is often prescribed to treat depression and anxiety. Schiele [33] used this drug to treat pseudoneurotic schizophrenia in hospitalized patients in Canada. In conclusion, the author expressed three thoughts: 1) pseudoneurotic schizophrenia is difficult to diagnose; 2) tranylcypromine and trifluoperzine are better tolerated with this type of mental disorder; 3 ) using phenalzine is less effective for correcting depressive disorders in the disease type in question. Nevertheless, the current instructions for phenalzine indicate that the drug can be used to treat atypical depression in adults, when other drugs are not effective and are not recommended for the treatment of pronounced depression and bipolar disorders (manic depression). The following combinations are recognized as dangerous: combinations of phenelzine with other ADs, MAOIs, 
carbamazepine, opiates, drugs containing L-DOPA and those influencing a dopamine metabolism. Its use is possible not earlier than five weeks after withdrawal of other ADs. Combinations of phenelzine with AP are undesirable due to the high risk of ADRs.

At the same time, Meyer et al. [34] published a clinical case and literature review of the use of phenelzine with AP (aripiprazole, quetiapine) in patients with therapeutic resistant unipolar depression. We analyzed 12 published cases of the above-mentioned combinations, focusing on pharmacological bases, with the development of serotonin syndrome and mechanisms that may not be associated with the risk of its development. Sokolski et al. [35] described the cases of using quetiapine for insomnia associated with refractory depression of the 42-year-old man. This case shows that low doses of quetiapine can represent an alternative form of therapy for phenelzine-induced insomnia. Nonetheless, the authors consider the described clinical case should be completed with the data from future study of a larger sample of patients to assess the effectiveness and safety of the drugs.

Moclobemide is the first reversible selective MAOI type A to become commercially available. It binds reversibly to the enzyme, considerably shortening the duration of its effect, reducing the risk of hypertensive crisis [36]. Silver et al. [37] were examined the effectiveness of adding moclobemide to antipsychotic treatment in schizophrenic patients with prominent negative symptoms. A significant improvement was seen on the Positive and Negative Syndrome Scale (PANSS) negative factor and for the Scale for the Assessment of Negative Symptoms (SANS) scores, PANSS total score, PANSS general factor score and Hamilton Depression Scale scores. Positive symptoms were not altered. Moclobemide augmentation may ameliorate negative, depressive and general symptoms in schizophrenia.

Moclobemide-induse ADRs have been well reported in several studies, mainly comparisons of moclobemide with standard ADs. The consensus has been that moclobemide produces fewer anticholinergic reactions and less orthostatic hypotension and dizziness than clomipramine or imipramine. The main problems reported early on were insomnia, agitation, and paresthesia. The most common ADRs in controlled trials have been insomnia and nausea [38]. Rare ADRs are acute confusion and agitation, hypomania, aggressive behavior and mild manic symptoms, which were described in severely depressed patients, refractory to other treatments, who took moclobemide [39].

\section{Selective serotonin reuptake inhibitors}

Selective serotonin reuptake inhibitors (SSRIs) are a number of ADs which prevent reuptake of neurotransmitters in the body. Known together as reuptake inhibitors, they prevent the reuptake of one or some neurotransmitters so that the majority of them are present and active in the brain. SSRIs work at the expense of specific inhibition of serotonin reuptake [40]. Some SSRIs as citalopram, escitalopram, sertraline, fluoxetine, and paroxetine are effective for treatment of depressive disorders in most cases of schizophrenia. The effectiveness of SSRIs is not immediate. Consequently, medication can take up to several weeks to be fully effective.

Buoli et al. [41] had studied the frequency of SSRIs prescriptions for patients with schizophrenia. Particular attention was paid to the SSRIs effect in the cases of negative, depressive, and obsessive-compulsive symptoms of schizophrenia. Unfortunately, in most studies, there was no data on statistically significant effects of SSRIs on the course of depression of patients with schizophrenia. However, the drugs of this group were reported to have an effect on the negative symptoms of schizophrenia. Specifically, paroxetine was described as the most effective drug of this group in the context of the considered problem of depressive disorders and schizophrenia comorbidity [42]. The study of SSRIs with obsessive-compulsive symptoms limited to the use of fluoxetine. The authors [43] came to the conclusion that to evaluate the simultaneous prescription of APs and ADs in schizophrenia, clinical and pharmacological monitoring is required, including the study of the level of drugs in the blood plasma - Therapeutic Drug Monitoring (TDM). Such 
approach is particularly relevant from the point of view of pharmacogenetics [44], as the risks of developing serious ADRs are much higher in patients with an unfavorable pharmacogenetic profile. It determines the necessity of introduction of deoxyribonucleic acid (DNA) profiling into clinical practice for patients suffering from schizophrenia and comorbid disorders [44-48].

However, when prescribing SSRIs, it is important to keep in mind the risk of developing hallucinations, including [49]: 1) visual hallucinations associated with sertraline [50];2) complex visual hallucinations associated with venlafaxine [51, 52];3) visual hallucinations and psychotic symptoms during the treatment of SSRIs involving the sigma receptors of the brain [53,54]; 4) visual hallucinations during the treatment of SSRIs and other ADs [55]; 5) visual and auditory hallucinations induced by paroxetine [56, 57]; 6) visual and auditory hallucinations, delusions induced by citalopram and escitalopram, described in young patients [58-60], as well as in patients of other age groups [61].

The mechanisms of this effect of SSRIs have not been sufficiently studied yet, but several hypotheses have been proposed. One of the hypotheses [44] is that people who have genetically determined increase in serotonin receptor sensitivity, have a higher risk of SSRI-induced hallucinations due to increased serotonin levels in the synaptic cleft in the serotonin receptor localization zone [62]. According to another hypothesis [63], this effect can be explained by the function of a protein known as the sigma receptor. Sigma receptors are; expressed in many regions of the brain and are involved in the regulation of cognitive functions, thinking, and perception [63-67]. The interaction of SSRIs with sigma receptors can cause SSRIs-induced psychosis in patients with schizophrenia [68]. The third hypothesis [63] is based on the functioning of the dopaminergic system of brain.

Most of the known neurochemical pathways of psychosis are caused by hyperstimulation of CNS. In 2002, Fortunati et al. [63] discovered an increased level of dopamine metabolites in patients with mania and psychosis, who were the ADRs of the use of SSRIs.

Helfer et al. [69] conducted a randomized controlled trial of ADs in schizophrenia and schizophrenic-like psychosis. The authors took into consideration the following parameters: age, duration of the disease, gender of patients, duration of use, and doses of all studied ADs, which were taken in combination with various APs for more than one week. The authors examined two primary symptoms (depressive disorders and cognitive disorders) and also secondary symptoms (positive symptoms of schizophrenia; ADRs; quality of life, etc.). In total, the authors studied 128 cases, including 82 randomized controlled trials. The median age of the patients was 28 years; $60 \%$ of the samples were male patients. The authors noted a high variability of the prescribed combinations of AD and AP. On average, patients took $31 \mathrm{mg}$ of fluoxetine per day (or an equivalent dose of another SSRI) and $604 \mathrm{mg}$ of chlorpromazine per day (or an equivalent dose of another AP). Of all the analyzed studies on the use of ADs, as well as adjunct therapy of APs, in comparison with the control group (the use of placebo or non-assignment of ADs), the following results were shown: a positive effect in the form of a decrease in the severity of depressive disorders in patients with schizophrenia with the use of SSRIs (in 42 studies involving 1849 patients); reduction of depressive disorders greater in patients receiving SSRIs against the control group, both in patients with schizophrenia, in those who have depressive disorders, and in patients with post psychotic depression [69].

The research by Buoli et al. [70] using the main database sources has been conducted to obtain an overview of the use and efficacy of SSRIs in schizophrenia. Data are too scanty to draw definitive recommendations. In a preliminary way, it can be said that available data do not show effectiveness of SSRIs on depressive symptoms of schizophrenia. Regarding negative symptoms, studies are contrasting, but paroxetine appears to be the most effective compound among SSRIs. Despite limited data, SSRIs appear to be useful for the treatment of obsessive-compulsive symptoms of schizophrenia, particularly fluvoxamine. Close clinical and pharmacological monitoring is needed in case of co-administration of APs and SSRIs for potential serious side effects and influence on plasma drug dosages. 


\section{Selective norepinephrine reuptake inhibitors}

Selective norepinephrine reuptake inhibitors (SNRIs) are a new type of ADs that works similarly to the previous group. SNRIs block only the monoamine transporter NET, excluding the other two monoamine transporters (DAT and SERT) for dopamine and serotonin [71]. SNRIs include reboxetine, maprotilin, atomoxetine, and viloxazine [72-74]. Unlike SSRIs, most ADs of this group have an ascending, rather than a flat, dose-dependent curve. SNRIs, similarly to SSRIs, can cause serotonin syndrome, which occurs when dangerously high levels of serotonin accumulate in the body and cause ADRs [75-77].

Raedler et al. [78] investigated the efficacy and safety of reboxetine in patients with schizophrenia, who have depressive or negative symptoms. Patients received both typical and atypical APs in the monotherapy mode, to which reboxetine added or not added (at a dose of 4-8 mg per day). The standard psychopathological study included assessment on the scales of Positive and Negative Syndrome Scale (PANSS), The Clinical Global Impression and Severity (CGI-S), The Clinical Global Impression and Improvement (CGI-I), Hamilton Depression Rating Scale (HAMD), and The Calgary Depression Scale for Schizophrenia (CDSS) before and after reboxetine treatment for a period of 26+-17 days. All patients with schizophrenia successfully tolerated combination therapy with reboxetine. Reboxetine-induced ADRs were not significant or were not recorded. All clinical scales (PANSS 93.1 vs. 63.1 points; CGI 5.4 vs. 4.1 points; HAMD 20.4 vs. 8.1 points; CDSS 12.5 vs. 4.6 points) showed statistically significant efficacy of riboxetine therapy $(\mathrm{p}<0.01)$. The authors came to the conclusion that adjuvant therapy with reboxetine for depressive or negative symptoms of schizophrenia is effective and safe.

Usall et al. [79] compared the efficacy and safety of reboxetine (SNRI) and citalopram (SSRI) as adjunct therapy to AP (risperidone and olanzapine) for the treatment of negative schizophrenia symptoms. To assess how often symptoms occur the authors used the PANSS and the Scale for Assessment of Negative Psychopathological Symptoms (SANS). A 6-month multicenter, randomized, double-blind, placebo-controlled trial showed that there were no statistically significant differences between the placebo group and the two study groups (riboxetin $+\mathrm{AP}$; citalopram $+\mathrm{AP}$ ) for positive or general psychopathology. The authors stated that the additional prescription of citalopram or reboxetine to risperidone or olanzapine for the treatment of negative symptoms of schizophrenia is not clinically justified, but this contradicts the results of previous studies.

Atomoxetine produces a widespread increase in brain norepinephrine and a secondary and selective increase in prefrontal dopamine. Given this, we evaluated atomoxetine's cognitive effects in a pilot placebo-controlled trial in patients with schizophrenia. Friedman et al. [80] are studied the safety and effectiveness of the use of atomoxetine together with second-generation APs in patients with schizophrenia, as well as the effect of this combination on the cognitive functions of patients. As a result of a placebo-controlled trial lasting for 8 weeks, patients received atomoxetine at a dose of 80 $\mathrm{mg}$ per day, compared to the placebo group. The state of cognitive functions was assessed on the scale of Brief Assessment of Cognition in Schizophrenia (BACS). The authors didn't find any statistically significant negative impact of atomoxetine on cognitive function in patients with schizophrenia. Nevertheless, atomoxetine treatment significantly increased the activity of working memory, due to the activation of the left dorsolateral prefrontal and left posterior cingulate cortex.

Shahzad et al. [81] are republished a Cochrane review of the safety of atomoxetine in patients with schizophrenia, in terms of its impact on cognitive functions, behavior, quality of patients' life as well as on social and general functioning. The authors stated a significant heterogeneity of earlier studies of atomoxetine in patients with schizophrenia. Also, they emphasized the need for conducting a large methodologically homogeneous study that could prove the positive effect of atomoxetine in the treatment of schizophrenia, in general, and cognitive functions impairment, in particular. 
However, systemic review and meta-analys by Solmi et al. [82] summarized the efficacy and safety of atomoxetine in schizophrenia. In results, no efficacy for atomoxetine on negative symptoms is proven. Also, many patients with schizophrenia on APs have already been under severe cardiovascular risk, and atomoxetine can cause even worse these symptoms (e.g., QT prolongation) [83].

\section{Tricyclic antidepressants}

Tricyclic antidepressants (TCAs) are a group of drugs used to treat depression, bipolar disorder, dysthymia (persistent depressive disorder), and MDD and other conditions such as chronic pain and insomnia [84 - 86]. TCAs include clomipramine, amoxapine, amitriptyline, desipramine, nortriptyline, and doxepin. The addition of TCAs to SSRIs has been used, with both positive and negative success. In the context of the current availability of newer drugs, this combination is used less and less often. Moreover, the addition of SSRIs to TCA can also lead to an increased level of TCAs in blood and slow their excretion from the body due to interaction at the level of CYP2D6 [87]. TCAs should not be used with certain MAOIs (tranylcypromine) due to the high risk of serious ADRs (malignant fever, convulsions, and death) [84]. Different TCAs have slightly different mechanisms of action, which leads to their similar ADRs. Common ADRs of TCA include anxiety, blurred vision, constipation, dizziness, drowsiness, increased appetite, muscle twitching, nausea, sweating, and weight gain [88].

Shoja-Shefti [89] studied the effectiveness of bromocriptine, fluoxetine and nortriptyline in dynamics and assessed the degree of reduction of negative symptoms of schizophrenia. One hundred schizophrenic patients in Razi psychiatric hospital were selected randomly and divided into four groups to take part in an open and controlled study. They received $2.5 \mathrm{mg}$ of bromocriptine, $20 \mathrm{mg}$ of fluoxetine, $25 \mathrm{mg}$ of nortriptyline, and placebo, respectively. Three weeks later, the dosage of the above-mentioned drugs was doubled. After another 3 weeks, it decreased, and the study was stopped. The presence and severity of negative symptoms of schizophrenia were evaluated at the beginning and before the start of taking these ADs on the SANS. As a result of the study, the authors reported that negative symptoms in the above-mentioned drug groups were reduced by placebo, bromocriptine, fluoxetine, and nortriptyline in $37.5 \%, 44 \%, 62.5 \%$, and $80 \%$ of patients, respectively. This decline was in most cases limited to only $20 \%$ percent of the baseline. Only in three cases in the nortriptyline group and in one case in the bromocriptine group this decrease reached $40 \%$ percent. There was no statistically significant difference between mild, moderate, and severe symptoms in response to treatment. In conclusion, the authors stated that bromocriptine, fluoxetine, and nortriptyline reduced negative symptoms in patients with schizophrenia. Among them, compared with placebo, nortriptyline was the most effective $(\mathrm{p}<0.005)$, and bromocriptine $(\mathrm{p}<0.75)$ was the weakest, while fluoxetine $(p<0.1)$ turned to be quite effective. There were no significant differences between nortriptyline and fluoxetine ( $\mathrm{p}<0.25)$, on the one hand, and between fluoxetine and bromocriptine $(p<0.25)$, on the other hand. Nonetheless, nortriptyline was significantly more effective than bromocriptine $(\mathrm{p}<0.01)$.

Apiquian et al. [90] conducted a prospective open-label study of amoxapine, starting with a fixed initial dose of $150 \mathrm{mg}$ per day with standardized titration up to $250 \mathrm{mg}$ per day. Positive, negative, and affective symptoms as well as ADRs were tracked using standardized weekly assessments. As a result, the authors concluded that amoxapine (at an average dosage of $210 \mathrm{mg}$ per day) was well tolerant and showed a significant improvement in both positive and negative symptoms in schizophrenia $(\mathrm{p}<0.001)$, a tendency to improve mood symptoms, and no extrapyramidal side effects resulting from treatment. This clinical evidence confirms that amoxapine may be a typical AP. Given the lack of weight gain and the fact that it is significantly cheaper than other TCAs options, amoxapine may be a valuable alternative for some schizophrenic patients with depressive disorders. 
However, TCAs are questionable in terms of adverse effects, drug-drug interactions and are generally not recommended in MDD, especially for elderly patients.

\section{Serotonin-norepinephrine reuptake inhibitors}

This group of serotonin-norepinephrine reuptake inhibitors (sNRIs) has a "dual effect" on monoaminergic systems. Blocking presynaptic alpha2-adrenergic receptors and removing their inhibitory effect on neurotransmission, they increase the functional activity of the noradrenergic and serotonergic systems. Hostility to the known subtypes of serotonin receptors causes the absence of a number of ADRs in SSRIs. This group includes venlafaxine and duloxetine.

Mazeh et al. [91] did a study of venlafaxine combinations prescribed for the correction of a depressive episode in patients with schizophrenia receiving basic AP therapy in two comparison groups (with or without the addition of venlafaxine to AP at an average dose of $146 \mathrm{mg}$ per day, with daily dose variation from 75 to $225 \mathrm{mg}$ ). Patients were observed for 6 weeks, in $74 \%$ of cases, statistically significant positive dynamics of the HDRS and CGIS scores were found. In most patients with combined therapy, there was a parallel decrease in the severity of psychotic symptoms. The authors concluded that venlafaxine may play a significant role in the treatment of depressive disorders in patients with schizophrenia without clinical symptoms of psychosis exacerbation.

Steen et al. [92] studied the concentration of venlafaxine and O-desmethylvenlafaxine in patients with bipolar disorders and schizophrenia. Also, they studied the relationship of the serum concentration of the studied ADs with the results of neuropsychological testing of verbal memory and learning ability, attention, working memory, executive functions, and data processing speed. The authors found a statistically significant positive association between the serum level of venlafaxine $+\mathrm{o}$-desmethylvenlafaxine and verbal memory when using the logical memory test (LMT) $(\mathrm{p}=0.015)$. Still, no statistically significant associations were found between serum levels of citalopram, escitalopram, and verbal memory. Furthermore, for all the studied ADs, there was no statistically significant association found between the patients' verbal learning, attention, working memory, executive functions, or data processing speed. However, venlafaxine had a better effect on verbal memory in patients with bipolar disorders and schizophrenia.

Cardinal et al. [93] studied an association between AP and AD therapy in hospitalized patients with schizophrenia using a Mental Health Case Register that lasted for 8 years (2005-2012) in the UK. Patients were included in the register with the diagnosis code F20, schizophrenia, according to the 10th revision of the International Statistical Classification of Diseases and Related Health Problems (ICD-10, 1995). The patients' condition was assessed before and after the therapy. The drugs were used for a 6-month period. According to the regression analysis, combinations sNRIs with aripiprazole, clozapine, and amisulpiride were associated with a fewer number of consecutive hospitalization days. In patients treated with clozapine, the additional prescription of mirtazapine was negatively associated with an increase in the number of hospitalization days. However, this effect was not shown when using sulpiride or venlafaxine. Besides, amisulpiride may be successful drug for negative symptoms of schizophrenia. In patients who did not receive clozapine, the effect of mirtazapine and venlafaxine did not significantly differ from the control group. Thus, the effect of mirtazapine was statistically independent of the effect of clozapine, although it was quantitatively more marked in patients taking clozapine.

The use of duloxetine in combination with AP in the treatment of patients with schizophrenia is possible. Nikbakhat et al. [94] conducted a double-blind placebo-controlled study to evaluate the efficacy and safety of duloxetine (at a dose of $60 \mathrm{mg}$ per day) compared with placebo in patients with schizophrenia while taking risperidone $(6 \mathrm{mg}$ per day). The authors showed in statistical terms significant improvement in the negative symptoms of schizophrenia ( $\mathrm{p}<0.001)$, the total number of points on the scale of assessment of positive and negative syndromes (PANSS) $(\mathrm{p}<0.001)$ and overall scores on the 
psychopathology subscale $(\mathrm{p}=0.001)$ in patients receiving duloxetine and risperidone therapy against the control group (placebo + risperidone).

Mico et al. [95] conducted 16-weeks randomized double-blind placebo-controlled study of the efficacy and safety of duloxetine, as an additional pharmacotherapy on clinical symptoms and cognitive functions in patients with resistant schizophrenia receiving clozapine in monotherapy mode. The dose of duloxetine was $60 \mathrm{mg}$ per day. A final sample of 33 patients completed the study. The authors showed a statistically significant decrease in the severity of negative and general psychopathological symptoms in patients with pharmacoresistant schizophrenia in the polytherapy group (duloxetine and clozapine) compared with the control group (placebo + clozapine). Meanwhile, there was no statistically significant effect of combination therapy on cognitive functions. This allowed the authors to conclude that the combination of duloxetine with clozapine is safe and tolerant in patients with schizophrenia.

\section{Norepinephrine and dopamine reuptake inhibitors}

Norepinephrine and dopamine reuptake inhibitors (NDRIs) are a modern group of ADs with minimal risk of ADRs and good tolerability. They block the action of the norepinephrine transporter and the dopamine transporter. NDRIs are used in clinical depression, narcolepsy, and can be used in case of schizophrenia. The only known representative of this class of ADs today is bupropion. The characteristics of bupropion include a low probability of inversion of the phase sign into mania or hypomania as well as a low probability of provocation of the "rapid cycle" (less than in SSRIs, and much less than in TCAs, MAOIs, and other powerful ADs). In this regard, bupropion is especially recommended for patients with bipolar depression, prone to phase inversion or the development of a" rapid cycle" in the treatment of various ADs [96]. According to mechanisms that are not fully studied, drugs of this class favorably affect the catecholaminergic, dopaminergic, and noradrenergic functions and do not affect the serotonergic system [97].

Bupropion is characterized by a general stimulating and psycho energizing effect (so clear that a number of specialists previously classified it not as an AD, but as a psychostimulant, despite the lack of narcotic properties). Bupropion has advantages in the treatment of sluggish-apathetic depressions and depressions in which anhedonia and reduced motivation predominate; it is also possible to use it as a corrector in the development of SSRI-induced apathy syndrome [97]. Normally, the drug is well tolerated, but agitation, nervousness, insomnia, anxiety, and gastrointestinal disorders may occur (mainly at the beginning of treatment). The drug is not recommended for use in patients with anorexia nervosa and bulimia due to its ability to reduce appetite. However, it may be useful in depressed patients with hyperphagia or in those who have gained excess weight during the treatment of TCAs. At the same time, some patients taking bupropion faced changes in behavior, the development of depression or aggravation of existing depressive symptoms, the appearance of suicidal thoughts and behavior.

Patel et al. [98] published a review and meta-analysis of the effectiveness of bupropion. Among the scales that were used in 21 studies analyzed by the authors there were HADS [99], Montgomery-Asberg Depression Assessment Scale (MADRS) [100], The inventory for depressive symptomatology (IDS) [101], and Structured Interview Guide for the Hamilton Depression Rating Scale - Seasonal Affective Disorders Version (SIGHSAD). [102]. Bupropion was effective in reducing depression scores in 24 of the 27 studies and, when evaluated, it showed comparable levels of efficacy to other ADs classes in favor of bupropion [103-107]. Hence, one study [108] didn't show statistically significant differences between the groups (AD, SSRI, SNRI, and TCA). The study by Hewett et al. [109] report a statistically significant difference in the average overall scores on the MADRS for bupropion and venlafaxine compared to placebo $(p=0.006$ and $p=0.001$, respectively). However, a larger follow-up trial of the same group [109] stated that there was no statistical significance of the average change in the least squares method compared to the initial MADRS at the end point of the study (8 weeks) for bupropion (180 $\mathrm{mg} /$ day) compared 
to a placebo. In the conclusion of the meta-analysis, the authors stated that the conducted studies, in general, showed a higher effectiveness of bupropion compared to other ADs. However, a significant number of studies did not have placebo, and only few trials were conducted for most ADs (sertraline - 5; fluoxetine - 2; paroxetine - 2; venlafaxine - 3; escitalopram -1 ; duloxetine -1 ; trazodone -1 ; and nortriptyline -1 ).

Englisch et al. [110] carried out a meta-analysis to evaluate the effectiveness of bupropion in depression, negative symptoms, and cognitive impairment in schizophrenia. In total, the final analysis included 13 randomized controlled trials (28 publications), 5 multiple case reports, 22 individual case reports, and 6 review articles. Data on the patient population, age, diagnosis, dose and composition of bupropion, AP and concomitant medications, ADR and treatment outcomes related to psychosis, affective and negative symptoms and cognitive function were collected from the found reports. A total of 30 cases of bupropion-induced psychosis were published, 17 (57\%) of which were associated with immediate-release drugs, and 28 (93\%) of which occurred without concomitant APs treatment. For comparison, 229 patients with schizophrenia who received stable AP regimens were successfully treated with bupropion, which in dynamics contributed to a noticeable clinical improvement in their condition without the development of psychosis. Pharmacokinetic reactions of bupropion with AP were rare, while electroencephalographic abnormalities occurred frequently. In schizophrenic patients treated with bupropion in addition to AP, the risk of psychosis caused by bupropion was low. According to this meta-analysis, the effectiveness of the NDRIs group in schizophrenia is biologically probable.

\section{Atypical antidepressants}

Atypical antidepressants (AADs) increase monoaminergic neurotransmission in the brain not by disrupting reuptake or inhibiting the destruction of biogenic amines, but by regulating the release of neurotransmitters through binding them to certain types of receptors in the CNS. However, vortioxetine also works as SSRI [111]. AADs are often used in patients with major depression, who have an inappropriate response or intolerant ADRs during the use of SSRIs as first-line drugs [112].

However, AADs are often a first-line drug, if this drug has the desired characteristics (for example, when using bupropion, ADRs in the form of sexual dysfunction and weight gain occurs less often than when taking SSRIs). AADs include agomelatine, mianserin, mirtazapine and trazodone. AAD-induced ADRs may differ depending on the medication type. However, dizziness, dry mouth, insomnia, nausea, vomiting, constipation, blurred vision, weight gain, and sexual dysfunction are the most common [113].

Mirtazapine does not exacerbate anxiety and agitation, has a lesser effect on sexual function and sleep (blockade of 5HT2A receptors), does not cause nausea, vomiting and other gastrointestinal disorders (blockade of 5HT3 receptors). The blockade of H1-histamine receptors determines the sedative effect of both drugs and increases the risk of weight gain while taking them. The sedative effect of these drugs in some cases can be considered as a desirable side effect, justifying their use in conditions accompanied by intense anxiety and / or agitation. At the same time, the original mechanism of action may determine the difficulty in selecting effective dosages [114].

Perry et al. [115] analyzed nine randomized controlled trials. Patients received either mirtazapine in combination with AP, or placebo in combination with AP. The results showed that adding mirtazapine to standard treatment for schizophrenia may slightly improve overall mental health, but does not have a clinically significant effect on negative symptoms. Adding mirtazapine to AP may slightly reduce the symptoms of AP-induced akathisia. In addition, some results showed that mirtazapine was associated with a higher risk of weight gain and sedation. Nevertheless, these results are based on evidence that is mostly of very poor quality.

Lee et al. [116] studied the tolerability of mirtazapine in patients with schizophrenia as an additional drug for the correction of negative symptoms in a randomized placebo- 
controlled trial lasting 8 weeks. Patients were treated with mirtazapine at a dose of $15 \mathrm{mg}$ per day for the first two weeks and $30 \mathrm{mg}$ per day for the next six weeks. The control group received only standard AP therapy and placebo. The assessment of negative symptoms and cognitive disorders was estimated using the Barnes Akathisia Rating Scale (BAS) and Simpson-Angus Scale for Extrapyramidal Symptoms (SAS). In addition, the authors evaluated such ADRs as akathisia, extrapyramidal syndrome, and weight gain as well as body mass index (BMI). Also, they compared mirtazapine-induced ADRs in patients receiving risperidone with the outcomes of risperidone monotherapy. No statistically significant events were found in the mirtazapine + risperidone group and in the placebo + risperidone group on the BAS and SAS scales. The weight increased by $5.83 \mathrm{~kg}$ during the 8 weeks of the study in the mirtazapine group. This effect was statistically significant compared to the placebo group. The incidence of AP-induced akathisia and extrapyramidal syndrome did not differ significantly in the comparison groups. Some other studies [116, 117] showed that the intake of mirtazapine in combination with other atypical APs (olanzapine, risperidone, or aripiprazole) in patients with depressive disorders induced the development of akathisia.

However, in a study by Lee J. [116], patients with comorbid depressive disorders were excluded, which may explain the discrepancy in the results. In addition, the data obtained by the authors differ from the results of Abbasi et al. [117], who found a statistically significant increase neither in weight nor in BMI of patients undergoing mirtazapine therapy. This might be due to the different duration of the case history of schizophrenia, the average dose of risperidone, the severity of psychopathological symptoms, and the sample size. As a rule, body weight gain induced by combination therapy with mirtazapine and AP is more often recorded in women suffering from schizophrenia, compared with men [117]. In general, the combination of mirtazapine with risperidone is tolerated satisfactorily with a positive effect on the severity of the negative symptoms of schizophrenia and the severity of depressive disorders. However, most authors draw attention to the need for dynamic control over the development of mirtazapine-induced weight.

Mathew [118] described clinical case and literature review of the mirtazapine use in patients with chronic schizophrenia receiving AP. A total of 4 randomized controlled trials and one open observational study were analyzed. Two studies demonstrated a statistically significant decrease in the overall score on the PANSS and SANS scales in patients receiving mirtazapine in combination with risperidone and clozapine. At the same time, the combination of mirtazapine with risperidone had a lower negative effect on cognitive functions. The author showed that the effectiveness of the combination of mirtazapine with olanzapine was the best therapeutic strategy. Yet, this review had limitations in the form of a small number of the analyzed studies. At the same time, the selection of the number of patients undergoing primary schizophrenia therapy, the mechanisms and long-term effects of combination therapy were not monitored.

Mutschler et al. [119] conducted a study of the effectiveness, safety and tolerability of ADs. The authors reported a series of consecutive clinical cases in seven patients with schizophrenia and concomitant severe depressive symptoms. All patients received agomelatine for a period of at least 6 weeks in addition to consistently standard doses of AP. General psychopathology, positive, negative, and depressive symptoms were assessed using standard interviews. According to the results of the study, the authors reported a significant reduction in depressive disorders. It was shown that the positive symptoms of schizophrenia remained unchanged, while the negative symptoms and general psychopathology significantly improved. Most patients with schizophrenia tolerated agomelatine well. The results of this study provide initial evidence that agomelatine is safe and effective in treating depressive symptoms in patients with schizophrenia. In addition, agomelatine is effective in treating the negative symptoms of schizophrenia [120122].

In the context of schizophrenia and depressive symptoms the mode of action of agomelatine is of special interest. Patients suffering from schizophrenia and comorbid 
major depression are difficult to treat, not least, because additionally these patients often suffer from negative symptoms. The antagonism of the 5 HT2C receptors and consecutive increase of dopamine and norepinephrine concentrations in the prefrontal cortex could be helpful concerning negative symptoms and anhedonia, often associated with major depression in schizophrenia [23]. The study by Mutschuler et al. [123] demonstrated effectiveness, good tolerability and safety of agomelatine in the treatment of depressive symptoms in patients suffering from schizophrenia. Moreover, negative symptoms improved in most patients. While one patient discontinued the treatment with agomelatine because of side effects, all other patients tolerated the medication well.

Stuhec et al. [124] identified a case with positive evidence of combination moclobemide and agomelatine relieving the symptoms of treatment-resistant MDD, which is otherwise difficult to manage. This case report may serve to help clinicians and clinical pharmacists as a new treatment option for treatment-resistant MDD, although further research is needed to confirm this practice.

Shiloh et al. [125] studied a combination of APs and mianserin. The study involved 18 hospitalized patients with schizophrenia who had an intense psychotic exacerbation of the disease. In a double-blind randomized trial, patients received $30 \mathrm{mg} /$ day of mianserin or placebo in combination with AP (haloperidol or perphenazine). Their mental status was assessed before, during, and at the end of 6 weeks of combined treatment using scales such as the Brief Psychiatric Assessment Scale (BPRS), The Scale for the Assessment of Positive Symptoms (SAPS), and HAMD. The group of patients receiving AP + mianserin showed a significantly greater improvement in overall BPRS indicators (17.6\% vs. $5.5 \%$; $p$ $=0.03)$ and a tendency to a greater improvement in SAPS indicators $(35.3 \%$ vs. $13.0 \%$; $p=$ 0.07). The authors concluded that in patients with therapeutic resistant schizophrenia together with an intense psychotic exacerbation, additional prescription of mianserin to the received AP may be effective. The favorable effect of APs in patients with pharmacoresistant schizophrenia is explained by a relatively high ratio of serotonergic and dopaminergic receptor blockade.

However, mianserin has not been available in many countries due to its safety problems. The main ADRs of mianserin are drowsiness and dizziness. Significant cognitive impairment is more likely with mianserin than with SSRIs, and weight gain is a common problem. The most serious ADRs of mianserin is a lowering of the white cell count, and fatal agranulocytosis has been reported [126].

\section{Discussion}

Our review showed that ADs are effective and can be prescribed for the correction of depressive disorders and negative symptoms in patients with schizophrenia when used in combination with APs. However, when co-prescribing ADs and APs, it is important to keep in mind the safety profile of specific combinations of drugs and their tolerability. Negative symptoms of schizophrenia, including those induced by a number of APs, are less correctable by AD monotherapy. The latter requires a long period of APs prescription (on average, 8 weeks), which may be limited in the real life of the patient outside the hospital [127]. Adding ADs to APs does not significantly increase the risk of developing psychosis. However, it can increase the individual risk of serious ADRs, although without increasing the risk of abdominal pain, dizziness, and dry mouth.

According to Helfer et al. [69], in comparison with the control group, trazodone, duloxetine, sertraline, amitriptyline, and IMAOs were the most effective drugs for the correction of depressive disorders in patients with schizophrenia. SSRIs can be used in patients with schizophrenia and depressive disorders. However, it is better to consider their use in cases where the use of ADs of other pharmacological groups is impossible. Also, it is worth mentioning that the negative symptoms of schizophrenia proved to be better corrected when using selegiline, duloxetine, fluvoxamine, mirtazapine, and SSRIs [128]. Clinical trials show that the additional use of AD together with AP for the correction 
of depressive disorders in schizophrenia may affect the cognitive functions of patients $[129,130]$.

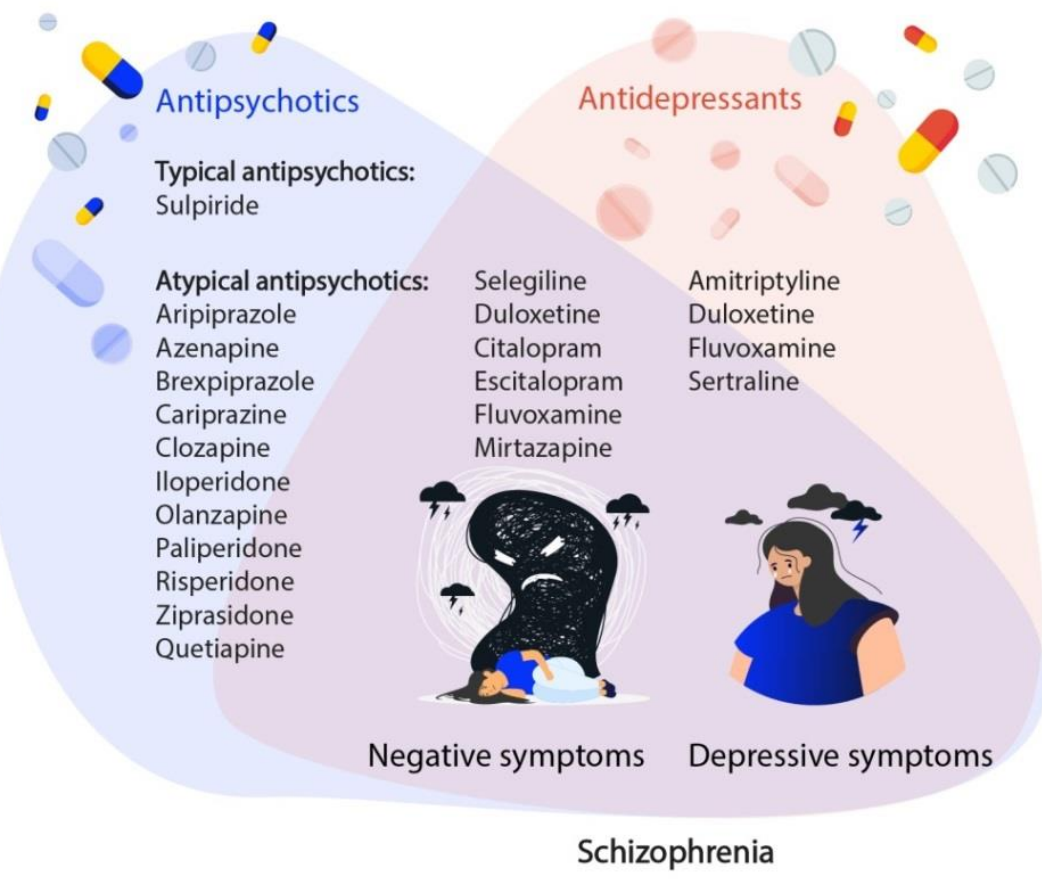

Figure 1. Antipsychotics and antidepressants for treatment of depressive and negative symptoms in schizophrenic patients.

The mechanism of this phenomenon is being studied in human and animal models of schizophrenia and is explained by the additive effect on CNS, especially in combination therapy with SSRIs and APs, which differ in effect compared to the use of exclusive treatment with AD or AP. Such changes are unique and are found in a component of the GABAergic system of the brain. Besides, these mechanisms can be explained by the different etiology and profile of genes expressed in peripheral mononuclear cells, which reflect the molecular processes in the central nervous system in patients with schizophrenia. Another way to study the mechanisms of the additive effect in the combined prescription of SSRIs and APs in schizophrenia is to change the profile of the genes expression in the serotonergic system of the CNS, the expression of matrix ribonucleic acid (RNA), including chemokine receptors, alpha receptors of chemokine 8, and others [131].

Harrison [132] published a review including 82 randomized controlled trials involving 3,486 patients with schizophrenia. The mean age of the patients was 40 years, and the mean duration of participation in the study was 8 weeks. The average mean duration of the disease since establishing the diagnosis of schizophrenia was 11.2 years. The study showed that ADs are safe when added to APs in general. At the same time, differences exist in the risk of exacerbation of psychosis and other ADRs between patients receiving different combinations of ADs and APs. This can be explained by the unfavorable pharmacological profile of patients, as evidenced by numerous studies [44]. However, in a review by Harrison et al. [132] pharmacogenetic aspects of the efficacy and safety of the combination of ADs and APs were not studied. 
Table 2. Possible antidepressant action mechanisms of antipsychotics [10, 11]

Antipsychotic

Amisulpirid

Aripiprazole

Asenapine

Brexiprazole
Possible action mechanism

5-HT7 antagonism

Presynaptic D2/3 autoreceptors antagonism

5-HT1A/2C receptor partial agonism

5-HT2A/2B receptor antagonism

5-HT6 receptor antagonism

Weak 5-HT7 receptor antagonism

D2/3 receptor partial agonism

Neuroprotective effects

5-HT2C/A2 receptor antagonism

5-HT6/7 receptor antagonism

5-HT2B receptor antagonism

Alpha2 adrenergic receptor antagonism

5-HT1A receptor partial agonism

5-HT1A receptor partial agonism

D2 receptor partial agonism

5-HT2A receptor partial antagonism

D2/3 receptor partial agonism

5-HT1A receptor partial agonism

5-HT2A / 5-HT7 antagonism

Iloperidone

5-HT2A receptor partial antagonism 5-HT6/7 receptor antagonism

5-HT6/7 receptor antagonism

5-HT1A receptor partial agonism

Lurasidone

Weak 5-HT2C receptor antagonism

Weak alpha2 adrenergic receptor antagonism

5-HT2A/2C receptor partial antagonism

5-HT7 receptor partial antagonism

5-HT2A receptor antagonism

Paliperidone

Alpha2 adrenergic receptor antagonism

5-HT7 receptor antagonism

Alpha2 adrenergic receptor antagonism

Quetiapine Norepinephrine transporter inhibition (metabolite)

5-HT7 receptor antagonism

5-HT2A receptor antagonism

Risperidone

Alpha2 adrenergic receptor antagonism

5-HT7 receptor antagonism

5-HT2A receptor antagonism

Sertindole

5-HT6/7 receptor antagonism 
In addition to ADs, some APs, have an antidepressant effect also (Figure 1). Some authors believe that concurrent treatment with antidepressants and antipsychotics (including traditional antipsychotics, such as sulpiride, or atypical antipsychotics, such as clozapine, olanzapine, quetiapine, aripiprazole, risperidone, cariprazine, ziprasidone, etc.) are more effective than monotherapy with antidepressants because this approach acts on multiple receptor systems (Table 2) $[2,11,133,134]$. These APs include aripiprazole, quetiapine, clozapine, and olanzapine when used in combination with AD (fluoxetine) [135]. An open-label randomized trial of individuals with treatment-resistant depression on high-dosage sertraline found that the patients had better scores on the Clinical Global Impression-Severity (CGI-S) scale after receiving adjunctive treatment with ziprasidone $160 \mathrm{mg} / \mathrm{d}$ compared with those who received adjunctive treatment with ziprasidone 80 $\mathrm{mg} / \mathrm{d}$ [136], but a retrospective study found that ziprasidone was effective for treatmentresistant depression, though there was no difference in effectiveness between ziprasidone and other atypical APs [137].

So, most studies showed that second-generation APs, which are also called atypical, have this effect and can be used to correct depressive disorders in patients with schizophrenia [138]. However, when using atypical APs with ADs in the treatment of depressed patients with schizophrenia, clinicians need to monitor patients for the emergence of ADRs [133].

\section{Limitations}

There are several limitations in our thematic research. We studied only English-language and Russian-language publications. It is likely that taking different medications can have a variable effect on depressive and negative symptoms in schizophrenia.

Most patients with schizophrenia are treated with polypharmacy, including other medications (e.g., antibiotics) and other medications that can worsen the symptoms of schizophrenia (e.g., delusions, hallucinations), which can lead to neglected AD-induced non-efficacy [139]. The authors should mention an increased risk of drug-drug interactions, especially important in elderly patients. This aspect has been excluded from the well-designed RCTs and meta-analysis, but it is important for daily practice. APs are especially problematic in this context, and therefore potential drug-drug interactions should be checked with different checkers before combination prescribing [140].

Further studies are needed to study the effect of modifiable (medications for depressive and negative symptoms in monotherapy and polytherapy, comorbid diseases, etc.) and unmodifiable (gender, age, genetic predisposition) predictors on safety in schizophrenic patients' treatment. However, the pharmacogenetic aspects of AD + AP combination therapy in patients with schizophrenia and depressive disorders have not been analyzed because such data were not taken into account and were not available in the early studies cited in this review. Also, further studies are needed to investigate the effects of carriage of ONVs/polymorphisms of genes encoding biomarkers on serum levels of ADs and APs in patients with schizophrenia.

Another limitation of this review is the problem with the conditional division of ADs into groups, since the same ADs can be included in different groups, or in one group of ADs. For example, bupropion is included in the group of NDRIs and AADs.

The comparison of the results of the studies we analyzed was limited by the combination of drugs, the duration of basic therapy for schizophrenia, and other factors (age, gender of patients, ethnic and racial group). The analyzed studies of the effectiveness and safety of use in patients with schizophrenia and depressive disorders had a different design, including methodological approaches for assessing the severity of negative symptoms and depressive disorders. At the same time, the following scales were most often used to evaluate the effectiveness of APs in combination with ADs: MADRS, SIGH-SAD, IDS, PANSS, CGI-S, CGI-I, HAMD, CDSS, SANS, BACS, BAS, SAS, BPRS, SAPS, and LMT. 
Most patients with schizophrenia are treated with polypharmacy, including other medications (e.g., antibiotics) and other medications that can worsen the symptoms of schizophrenia (e.g., delusions, hallucinations), which can lead to neglected AD-induced non-efficacy.

Finally, the studies of ADs for the treatment of depressive and negative symptoms in schizophrenia analyzed by us are very different on samples.

\section{Conclusions}

Modern approaches to the treatment of depressive disorders in patients suffering from schizophrenia vary in different countries, but most of the ADs used in clinical psychiatric practice are widely used to treat this comorbid condition. The efficacy and safety of ADs of the different classes considered in this review depends on their mechanisms of action, duration of admission, type of APs taken, and specific clinical situation (acute depressive disorder, major depressive episode, or chronic depressive episode). Most promising in clinical practice are SNRIs and dual ADs. The use of TCAs is limited due to the higher risk of ADRs. The use of most SSRIs is limited due to the risk of aggravation of hallucinations (this risk being higher for patients with visual hallucinations, and lower for those with auditory hallucinations) and $\backslash$ or iatrogenic psychosis. These ADRs may probably occur in patients suffering from schizophrenia due to their ideal "poor metabolizer" pharmacogenetic profile, since most of the drugs considered in this review have hepatic metabolism.

Author Contributions: Conceptualization, R.F.N.; methodology A.D.S.; software, M.A.N.; formal analysis, M.A.N.; investigation, A.R.A.; M.A.N.; resources, A.V.P. data curation, M.A.N.; writingoriginal draft preparation, M.A.N. A.D.S.; writing-review and editing, R.F.N.; O.A.G.; visualization, A.V.P.; supervision, R.N.F.; project administration, R.N.F.

All authors have read and agreed to the published version of the manuscript.

Funding: This research received no external funding.

Acknowledgments: We acknowledge Ekaterina V. Kachura (katy.kachura@mail.ru) for preparing the figure for the article.

Conflicts of Interest: The authors declare no conflict of interest.

\section{References}

1. Van Os, J.; Kenis, G.; Rutten, B. The environment and schizophrenia. Nature 2010, 468, 203-212. doi: 10.1038/nature09563

2. Kaluev, A.V.; Demin, K.A.; Donbass, A.D. Genomic mechanisms of anxiety and depression pathogenesis in experimental models. Review of Psychiatry and Medical Psychology named after V.M. Bekhterev 2019, (4-1): 48-50. In Russian doi: 10.31363/23137053-2019-4-1-48-50

3. Addington, D.; Addington, J. Attempted suicide and depression in schizophrenia. Acta Psychiatrica Scandinavica 1992, 85:288-291.

4. Chemerinski, E.; Bowie, C.; Anderson, H.; Harvey, P.D. Depression in schizophrenia: methodological artifact or distinct feature of the illness? The Journal of Neuropsychiatry and Clinical Neurosciences 2008, 20(4), 431-440. doi: 10.1176/jnp.2008.20.4.431

5. Hicks, J.K.; Sangkuhl, K.; Swen, J.J.; Ellingrod, V.L.; Müller, D.J.; Shimoda, K.; Bishop, J.R.; Kharasch, E.D.; Skaar, T.C.; Gaedigk, A.; Dunnenberger, H.M.; Klein, T.E.; Caudle, K.E.; Stingl, J.C. Clinical pharmacogenetics implementation consortium guideline (CPIC) for CYP2D6 and CYP2C19 genotypes and dosing of tricyclic antidepressants: 2016 update. Clin Pharmacol Ther. 2017, 102(1), 37-44. doi: 10.1002/cpt.597. 
6. Kirchheiner, J.; Nickchen, K.; Bauer, M.; Wong, M.R.; Licinio, J.; Roots, I.; Brockmöller, J. Pharmacogenetics of antidepressants and antipsychotics: the contribution of allelic variations to the phenotype of drug response. Molecular Psychiatry 2004, 9, 442-473. https://doi.org/10.1038/sj.mp.4001494

7. Vaiman, E.E.; Novitsky, M.A.; Nasyrova, R.F. Pharmacogenetics of chlorpromazine and its role in the development of antipsychotic-induced parkinsonism. Personalized Psychiatry and Neurology. 2021; 1(1): 11-17. https://doi.org/10.52667/27129179-2021-1-1-11-17.

8. Abdyrakhmanova, A.K.; Shnayder, N.A.; Neznanov, N.G.; Nasyrova, R.F. Pharmacogenetics of quetiapine. Personalized Psychiatry and Neurology. 2021; 1(1): 73-83. https://doi.org/10.52667/2712-9179-2021-1-1-73-83

9. Nasyrova, R.F.; Shnayder, N.A.; Mironov, K.O.; Shipulin, G.A.; Dribnokhodova, O.P.; Golosov, E.A.; Tolmachev, M.Y.; Andreev, B.P. Pharmacogenetics of schizophrenia in real clinical practice: A clinical case. Neurology, Neuropsychiatry, Psychosomatics 2018, 10(4): 88-93. doi: 10.14412/2074-2711-2018-4-88-93

10. Han, C.; Wang, S.M.; Kato, M.; Lee, S.J.; Patkar, A.A.; Masand, P.S.; Pae, C.U. Second-generation antipsychotics in the treatment of major depressive disorder: current evidence. Expert Rev Neurother. 2013 ;13(7): 851-70. doi: 10.1586/14737175.2013.811901.

11. Wang, S.M.; Han, C.; Lee, S.J.; Jun, T.Y.; Patkar, A.A.; Masand, P.S.; Pae, C.U. Second Generation Antipsychotics in the Treatment of Major Depressive Disorder: An Update [published correction appears in Chonnam Med J. 2019 Jan;55(1):73]. Chonnam Med J. 2016; 52(3): 159-172. doi:10.4068/cmj.2016.52.3.159

12. Ulrich, S.; Messer, T. Review and meta-analysis of add-on tranylcypromine with antipsychotic drugs for the treatment of schizophrenia with predominant negative symptoms: a restoration of evidence. Current Medical Research and Opinion 2021, 37(7): 1233-1248. doi: 10.1080/03007995.2021.1895095.

13. Kampling, H.; Baumeister, H.; Bengel, J.; Mittag, O. Prevention of depression in adults with long-term physical conditions. The Cochrane Database of Systematic Reviews 2021, 3(3). doi: 10.1002/14651858.CD011246.pub2.

14. Nussbaumer-Streit, B.; Thaler, K.; Chapman, A.; Probst, T.; Winkler, D.; Sönnichsen, A.; Gaynes, B.N.; Gartlehner, G. Second-generation antidepressants for treatment of seasonal affective disorder. The Cochrane Database of Systematic Reviews 2021, 3. doi: 10.1002/14651858.CD008591.pub3.

15. Wilson, M.; Tripp, J. Clomipramine. [Updated 2021 Jan 26]. In: StatPearls [Internet]. Treasure Island (FL): Stat Pearls Publishing 2021 Jan. Available from: https://www.ncbi.nlm.nih.gov/books/NBK541006. PMID: 31082050.

16. Yang, Y.; Guangrong, Z.; Xiaojing, W.; Gu, W. Fine-tuning pharmacological properties of mirtazapine antidepressant drug: a theoretical study. Journal of Biomolecular Structure and Dynamics 2021, 9:1-9. doi: 10.1080/07391102.2021.1896386

17. Majeed, A.; Xiong, J.; Teopiz, K.M.; Ng, J.; Ho, R.; Rosenblat, J.D.; Phan, L.; Cao, B.; McIntyre, R.S. Efficacy of dextromethorphan for the treatment of depression: A systematic review of preclinical and clinical trials. Expert Opinion on Emerging Drugs 2021, 26(1):63-74. doi: 10.1080/14728214.2021.1898588.

18. Huecker, M.R.; Smiley, A.; Saadabadi, A. Bupropion. 2021 Apr 19. In: Stat Pearls [Internet]. Treasure Island (FL): StatPearls Publishing; 2021 Jan. PMID: 29262173.

19. Maeda, I.; Inoue, S.; Uemura, K.; Tanimukai, H.; Hatano, Y.; Yokomichi, N.; Amano, K.; Tagami, K.; Yoshiuchi, K.; Ogawa, A.; Iwase, S. Phase-r delirium study group. Low-dose trazodone for delirium in patients with cancer who received specialist palliative care: a multicenter prospective study. Journal of Palliative Medicine 2021, 24(6): 914-918. doi: 10.1089/jpm.2020.0610

20. Laban, T.S.; Saadabadi, A. Monoamine oxidase inhibitors (MAOI). National Center for Biotechnology Information, U.S. National Library of Medicine. Published April 7, 2019. Available from: https://www.ncbi.nlm.nih.gov/books/NBK539848/

21. Baker, G.B.; Coutts, R.T.; McKenna, K.F.; Sherry-McKenna, R.L. Insights into the mechanisms of action of the MAO inhibitors phenelzine and tranylcypromine: a review. Journal of Psychiatry and Neuroscience 1992, 17(5): 206-214. PMID: 1362653 
22. Thomas, S.J.; Shin, M.; McInnis, M.G.; Bostwick, J.R. Combination therapy with monoamine oxidase inhibitors and other antidepressants or stimulants: strategies for the management of treatment-resistant depression. Pharmacotherapy 2015, 35(4):433-49. doi: 10.1002/phar.1576.

23. Krishnan, K. Revisiting monoamine oxidase inhibitors. Journal of Clinical Psychiatry 2007, 68(8):35-41. PMID: 17640156

24. Hodgman, M.J.; Martin, T.G.; Krenzelok, E.P. Serotonin syndrome due to venlafaxine and maintenance tranylcypromine therapy. Human and experimental toxicology 1997, 16: 14-17. doi: 10.1177/0960327197016001031

25. Brubacher, J.R.; Hoffman, R.S.; Lurin, M.J. Serotonin syndrome from venlafaxine-tranylcypromine interaction. Veterinary and Human Toxicology 1996, 38: 358-361. PMID: 8888541

26. Keltner, N.; Harris, C.P. Serotonin syndrome: a case of fatal SSRI/MAOI interaction. Perspectives in Psychiatric Care 1994, 30: 26-31. doi: 10.1111/j.1744-6163.1994.tb00446.x

27. Neuvonen, P.J.; Pohjola-Sintonen, S.; Tacke, U.; Vuori, E. Five fatal cases of serotonin syndrome after moclobemidecitalopram or moclobemide-clompiramine overdoses. The Lancet 1993, 342: 1419. doi: 10.1016/0140-6736(93)92774-n

28. Rapaport, M.H. Dietary restrictions and drug interactions with monoamine oxidase inhibitors: the state of the art. The Journal of Clinical Psychiatry 2007, 68(8) :42-46. PMID: 17640157

29. Nierenberg, A.A.; Keck, P.E. Management of monoamine oxidase inhibitor-associated insomnia with trazodone. Journal of Clinical Psychopharmacology 1989, 9: 42-45. PMID: 2708555

30. Jacobsen, F.M. Low-dose trazodone as a hypnotic in patients treated with MAOIs and other psychotropics: a pilot study. The Journal of Clinical Psychiatry 1990, 51: 298-302; PMID: 2365668

31. Zetin, M. Combined use of trazodone and phenelzine in depression: case report. The Journal of Clinical Psychiatry 1984, 45: 182-183. PMID: 6715295

32. Ulrich, S.; Messer, T. Review and meta-analysis of add-on tranylcypromine with antipsychotic drugs for the treatment of schizophrenia with predominant negative symptoms: a restoration of evidence. Current Medical Research and Opinion 2021, 37(7): 1233-1248. doi: 10.1080/03007995.2021.1895095

33. Schiele, B.C. Treatment of pseudoneurotic schizophrenics and chronic neurotics. The Canadian Journal of Psychiatry 1962, 7: 60-66. doi: 10.1177/070674376200701s11.

34. Meyer, J.M.; Cummings, M.A.; Proctor, G. Augmentation of phenelzine with aripiprazole and quetiapine in a treatmentresistant patient with psychotic unipolar depression: case report and literature review. CNS Spectrums 2017, 22(5): 391-396. doi: $10.1017 / S 1092852916000821$

35. Sokolski, K.N.; Brown, B.J. Quetiapine for insomnia associated with refractory depression exacerbated by phenelzine. Annals of Pharmacotherapy 2006, 40(3) :567-570. doi: 10.1345/aph.1G416

36. Tiller, J.W. The new antidepressants - clinical applications. Aust Prescr 1999; 22: 108-111

37. Silver, H.; Aharon, N.; Hausfater, N.; Jahjah, N. The effect of augmentation with moclobemide on symptoms of schizophrenia. Int Clin Psychopharmacol. 1999; 14(3): 193-195. PMID: 10435775

38. Bonnet, U. Moclobemide: therapeutic use and clinical studies. CNS Drug Rev. 2003; 9(1): 97-140. doi: 10.1111/j.15273458.2003.tb00245.x

39. Fahy, T. Side effects of moclobemide in depressed patients refractory to other treatments. Irish Journal of Psychological Medicine 1993; 10(1), 24-27. doi:10.1017/S0790966700013264

40. Danilov, D.S. Antidepressants are selective serotonin neuronal reuptake inhibitors: 40-year history. Neurology, Neuropsychiatry, Psychosomatics 2015, 1(7): 66-74. doi: 10.14412/2074-2711-2015-1-66-74

41. Buoli, M.; Serati, M.; Ciappolino, V.; Altamura, A.C. May selective serotonin reuptake inhibitors provide some benefit for the treatment of schizophrenia? Expert Opinion on Pharmacotherapy 2016, 17(10): 1375-1385. doi: 10.1080/14656566.2016.1186646. 
42. Purgato, M.; Papola, D.; Gastaldon, C.; Trespidi, C.; Magni, L.R.; Rizzo, C.; Furukawa, T.A.; Watanabe, N.; Cipriani, A.; Barbui, C. Paroxetine versus other anti-depressive agents for depression. Cochrane Database of Systematic Reviews 2014, 3(4). doi: 10.1002/14651858.

43. Micheli, L.; Ceccarelli, M.; D'Andrea, G.; Tirone, F. Depression and adult neurogenesis: Positive effects of the antidepressant fluoxetine and of physical exercise. Brain Research Bulletin 2018, 143: 181-193. doi: 10.1016/j.brainresbull.2018.09.002.

44. Clinical psychopharmacogenetics, ed. by R.F. Nasyrova and N.G. Neznanov. - SPb: DEAN Publishing House, 2019,405 p. ISBN 978-5-6043573-7-8.

45. Serretti, A.; Artioli, P. The pharmacogenomics of selective serotonin reuptake inhibitors. Pharmacogenomics J 2004, (4) 233244. https://doi.org/10.1038/sj.tpj.6500250

46. Kronenberg, S.; Frisch, A.; Rotberg, B.; Carmel, M.; Apter, A.; Weizman, A. Pharmacogenetics of selective serotonin reuptake inhibitors in pediatric depression and anxiety. Pharmacogenomics 2008; 9(11): 1725-1736. doi: 10.2217/14622416.9.11.1725.

47. Osis, L.; Bishop, J.R. Pharmacogenetics of SSRIs and sexual dysfunction. Pharmaceuticals 2010; 3(12): $3614-3628$. https://doi.org/10.3390/ph3123614

48. Fabbri, C.; Minarini, A.; Niitsu, T.; Serretti, A. Understanding the pharmacogenetics of selective serotonin reuptake inhibitors. Expert Opin Drug Metab Toxicol 2014; 10(8): 1093-1118. doi: 10.1517/17425255.2014.928693

49. Cancelli, I.; Marcon, G.; Balestrieri, M. Factors associated with complex visual hallucinations during antidepressant treatment. Hum Psychopharmacol 2004 19(8): 577-584. doi: 10.1002/hup.640

50. Marcon, G.; Cancelli, I.; Zamarian, L.; Bergonzi, P.; Balestrieri, M. Visual hallucinations with sertraline. The Journal of Clinical Psychiatry 2004, 65(3): 446-447. doi: 10.4088/jcp.v65n0322f

51. Tripp, A.C.; Golden, S.A. Transient complex visual hallucinations with venlafaxine treatment: a case report. Prim Care Companion J Clin Psychiatry 2009; 11(2): 83. doi:10.4088/pcc.08100647

52. Jacob, M.K.; Ash, P. Venlafaxine-induced complex visual hallucinations in a 17-year-old boy. J Clin Psychiatry 2009; 70(4): 601-603. doi: 10.4088/jcp.08104627

53. Schuld, A.; Archelos, J.J.; Friess, E. Visual hallucinations and psychotic symptoms during treatment with selective serotonin reuptake inhibitors: is the sigma receptor involved? Journal of Clinical Psychopharmacology 2000, 20(5): 579-580. doi: 10.1097/00004714-200010000-00014

54. Safeekh, A.T.; Pinto, D. Venlafaxine-induced psychotic symptoms. Indian J Psychiatry 2009; 51(4): 308-309. doi: 10.4103/0019-5545.58301.

55. Cancelli, I.; Marcon, G.; Balestrieri, M. Factors associated with complex visual hallucinations during antidepressant treatment. Human Psychopharmacology Clinical and Experimental 2004, 19(8): 577-84. doi: 10.1002/hup.640

56. Monji, A.; Kato, T.; Mizoguchi, Y.; Horikawa, H.; Seki, Y.; Kanba, S. Visual and auditory hallucinations during normal use of paroxetine for treatment of major depressive disorder. The Journal of Neuropsychiatry and Clinical Neurosciences 2011, 23(4): 14-15. doi: 10.1176/jnp.23.4.jnpe14

57. Tanikawa, C.; Kamatani, Y.; Terao, C.; Usami, M.; Takahashi, A.; Momozawa, Y.; Suzuki, K.; Ogishima, S.; Shimizu, A.; Satoh, M.; Matsuo, K.; Mikami, H.; Naito, M.; Wakai, K.; Yamaji, T.; Sawada, N.; Iwasaki, M.; Tsugane, S.; Kohri, K.; Yu, A.S.L.; Yasui, T.; Murakami, Y.; Kubo, M.; Matsuda, K. Novel risk loci identified in a genome-wide association study of urolithiasis in a Japanese population. J Am Soc Nephrol 2019; 30(5): 855-864. doi: 10.1681/ASN.2018090942.।

58. Capaldi, V.F.; Carr, R.B. Citalopram-induced hallucinations and delusions in a young adult. General Hospital Psychiatry 2010, 32(6): 648. e1-3. doi: 10.1016/j.genhosppsych.2010.07.008.

59. Mowla, A.; Khosravizadegan, F.; Ebrahimi, A.A.; Sabayan, B.; Pani, A. Citalopram associated with complex visual hallucination: a case report. Prog Neuropsychopharmacol Biol Psychiatry. 2009; 30;33(3): 575-576. doi: 10.1016/j.pnpbp.2009.01.011. 
60. Moorthy, S.; Arthur, P. Visual and auditory hallucinations associated with escitalopram in a young male. The Journal of Medical Research 2018; 4(6): 256-257. doi:10.31254/jmr.2018.4601

61. Waltereit, R.; Eifler, S.; Schirmbeck, F.; Zink, M. Visual and auditory hallucinations associated with citalopram treatment. Journal of Clinical Psychopharmacology 2013, 33(4): 583-584. doi: 10.1097/JCP.0b013e31829771ca

62. Taam, M.A.; de Boissieu, P.; Taam, R.A.; Breton, A.; Trenque T. Drug-induced hallucination: A case/non case study in the French Pharmacovigilance Database Eur. J. Psychiat. 2015, 29(1): 21-31. doi: 10.4321/S0213-61632015000100002

63. Fortunati, F.; Mazure, C.; Preda, A.; Wahl, R.; Bowers, M.Jr. Plasma catecholamine metabolites in antidepressantexacerbated mania and psychosis. Journal of Affective Disorders 2002, 68(2-3): 331-334. doi: 10.1016/s0165-0327(00)00327-x

64. Hayashi, T.; Su, T. The sigma receptor: evolution of the concept in neuropsychopharmacology. Curr Neuropharmacol 2005;3(4): 267-280. doi:10.2174/157015905774322516

65. Malik, M.; Rangel-Barajas, C.; Sumien, N.; Su, C.; Singh, M.; Chen, Z.; Huang, R.Q.; Meunier, J.; Maurice, T.; Mach, R.H.; Luedtke, R.R. The effects of sigma $(\sigma 1)$ receptor-selective ligands on muscarinic receptor antagonist-induced cognitive deficits in mice. Br J Pharmacol 2015 ; 172(10): 2519-2531. doi: 10.1111/bph.13076.

66. Penke, B.; Fulop, L.; Szucs, M.; Frecska, E. The Role of Sigma-1 Receptor, an Intracellular Chaperone in Neurodegenerative Diseases. Curr Neuropharmacol 2018; 16(1) :97-116. doi:10.2174/1570159X15666170529104323.

67. Hunt, M.J.; Kopell, N.J.; Traub, R.D.; Whittington, M.A. Aberrant Network Activity in Schizophrenia. Trends Neurosci 2017; 40(6): 371-382. doi:10.1016/j.tins.2017.04.003

68. Schuld, A.; Archelos, J.J.; Friess, E. Visual hallucinations and psychotic symptoms during treatment with selective serotonin reuptake inhibitors: is the sigma receptor involved? J Clin Psychopharmacol 2000; 20(5): 579-80. doi: 10.1097/00004714200010000-00014

69. Helfer, B.; Samara, M.T.; Huhn, M.; Klupp, E.; Leucht, C.; Zhu, Y.; Engel, R.R.; Leucht,aS. Efficacy and safety of antidepressants added to antipsychotics for schizophrenia: a systematic review and meta-Analysis. American Journal of Psychiatry 2016, 1;173(9): 876-86. doi: 10.1176/appi.ajp.2016.15081035.

70. Buoli, M; Serati, M.; Ciappolino, V.; Altamura, A.C. May selective serotonin reuptake inhibitors (SSRIs) provide some benefit for the treatment of schizophrenia? Expert Opin Pharmacother 2016; 17(10): 1375-1385. doi: 10.1080/14656566.2016.1186646.

71. Drobizhev, M.Y. Selective serotonin and norepinephrine reuptake inhibitors. Psychiatry and Psychopharmacotherapy named after P.B. Gannushkin 2005, 4: 217-223.

72. Perahia, D.G.; Pritchett, Y.L.; Kajdasz, D.K.; Bauer, M.; Jain, R.; Russell, J.M.; Walker, D.J.; Spencer, K.A.; Froud, D.M.; Raskin, J.; Thase, M.E. A randomized, double-blind comparison of duloxetine and venlafaxine in the treatment of patients with major depressive disorder. Journal of Psychiatric Research 2008, 42(1): 22-34. doi: 10.1016/j.jpsychires.2007.01.008.

73. Nemeroff, C.B.; Schatzberg, A.F.; Goldstein, D.J.; Detke, M.J.; Mallinckrodt, C.; Lu, Y.; Tran, P.V. Duloxetine for the treatment of major depressive disorder. Psychopharmacology Bulletin 2002, 36(4): 106-132. PMID: 12858150.

74. Nelson, J.C.; Pritchett. Y.L.; Martynov, O.; Yu J.Y.; Mallinckrodt, C.H.; Detke M,J. The safety and tolerability of duloxetine compared with paroxetine and placebo: a pooled analysis of 4 clinical trials. Primary Care Companion to The Journal of Clinical Psychiatry 2006, 8(4): 212-219. doi: 10.4088/pcc.v08n0404.

75. Raskin, J.; Goldstein, D.J.; Mallinckrodt, C.H.; Ferguson, M.B. Duloxetine in the long-term treatment of major depressive disorder. The Journal of Clinical Psychiatry 2003, 64(10): 1237-1244. doi: 10.4088/jcp.v64n1015

76. Rickels, K.; Downing, R.; Schweizer, E.; Hassman, H. Antidepressants for the treatment of generalized anxiety disorder. A placebo-controlled comparison of imipramine, trazodone, and diazepam. Archives of General Psychiatry 1993, 50(11): 884-895. doi: 10.1001/archpsyc.1993.01820230054005.

77. Rudolph, R.L.; Entsuah, R.; Chitra, R. A meta-analysis of the effects of venlafaxine on anxiety associated with depression. Journal of Clinical Psychopharmacology 1998, 18(2): 136-144. doi: 10.1097/00004714-199804000-00006. 
78. Raedler, T. J.; Jahn, H.; Arlt, J.; Kiefer, F.; Schick, M.; Naber, D.; \& Wiedemann, K. Adjunctive use of reboxetine in schizophrenia. European Psychiatry 2004, 19(6), 366-369. doi: 10.1016/j.eurpsy.2004.06.017

79. Usall, J.; López-Carrilero, R.; Iniesta, R.; Roca, M.; Caballero, M.; Rodriguez-Jimenez, R.; Oliveira, C.; Bernardo, M.; Corripio, I.; Sindreu, S.D.; González Piqueras, J.C.; Felipe, A.E.; Fernandez de Corres, B.; Ibáñez, A.; Huerta, R.; Abordaje síntomas negativos esquizofrenia group. Double-blind, placebo-controlled study of the efficacy of reboxetine and citalopram as adjuncts to atypical antipsychotics for negative symptoms of schizophrenia. The Journal of Clinical Psychiatry 2014, 75(6): 608615. doi: 10.4088/JCP.13m08551. PMID: 25004184

80. Friedman, J.I.; Carpenter, D.; Lu, J.; Fan, J.; Tang, C.Y.; White, L.; Parrella, M.; Bowler, S.; Elbaz, Z.; Flanagan, L.; Harvey, P.D. A pilot study of adjunctive atomoxetine treatment to second-generation antipsychotics for cognitive impairment in schizophrenia. Journal of Clinical Psychopharmacology 2008, 28(1): 59-63. doi: 10.1097/jcp.0b013e318161318f.

81. Shahzad, A.M.; Javed, Z.; \& Kumar, A. Atomoxetine for schizophrenia. Cochrane Database of Systematic Reviews 2014. doi: 10.1002/14651858.cd011035

82. Solmi, M.; Fornaro, M.; Toyoshima, K.; Carvalho, A.F.; Köhler, C.A.; Veronese, N.; Stubbs, B.; de Bartolomeis, A.; Correll, C.U. Systematic review and exploratory meta-analysis of the efficacy, safety, and biological effects of psychostimulants and atomoxetine in patients with schizophrenia or schizoaffective disorder. CNS Spectr 2019; 24(5): 479-495. doi: $10.1017 / S 1092852918001050$

83. Štuhec, M.; Švab, V. Atomoxetine-induced life-threatening long QT syndrome. Ir J Med Sci 2013; 182: 535-537. https://doi.org/10.1007/s11845-013-0925-y

84. Purse, M. Overview of tricyclic antidepressants. Older-generation drugs still have their place in treatment: in Very Well Mind. Available: https://www.verywellmind.com/tricyclic-antidepressants-379652. Updated on October 05.2020

85. Moraczewski J, Aedma KK. Tricyclic Antidepressants. [Updated 2020 Dec 7]. In: StatPearls [Internet]. Treasure Island (FL): StatPearls Publishing; 2021 Jan-. Available from: https://www.ncbi.nlm.nih.gov/books/NBK557791/

86. Depression: How effective are antidepressants? National Center for Biotechnology Information. Updated Jan 12, 2017 Available: https://www.ncbi.nlm.nih.gov/books/NBK361016/

87. Skarl S. Anxiety and Depression Association of America. Medication. Journal of Consumer Health on the Internet 2015, 19(2): 100-106. doi: 10.1080/15398285.2015.1035595

88. Bauer, M.; Pfennig, A.; Severus, E.; Weybrau, P.S.; Angst, J.; Müller, H-Yu. Clinical guidelines of the World Federation of Societies of Biological Psychiatry (WFPS) for Biological Therapy of Unipolar Depressive. Modern Therapy of Mental Disorders $2016,4: 33-39$.

89. Shoja-Shefti, S. Effectiveness of bromocriptine, fluoxetine and nortriptyline in ameliorating the negative symptoms of schizophrenia. Current Psychopharmacology 2019, 5 (1 and 2): 58-63

90. Apiquian, R.; Ulloa, E.; Fresan, A.; Loyzaga, C.; Nicolini, H.; Kapur, S. Amoxapine shows atypical antipsychotic effects in patients with schizophrenia: results from a prospective open-label study. Schizophrenia Research 2003, 59(1): 35-9. doi: 10.1016/s0920-9964(01)00342-5. PMID: 12413640.

91. Mazeh, D.; Shahal, B.; Saraf, R.; Melamed, Y. Venlafaxine for the treatment of depressive episode during the course of schizophrenia. Journal of Clinical Psychopharmacology 2004, 24(6): 653-655. doi: 10.1097/01.jcp.0000144894.37611.0a.

92. Steen, N.E.; Aas, M.; Simonsen, C.; Dieset, I.; Tesli, M.; Nerhus, M.; Gardsjord, E.; Mørch, R.; Agartz, I.; Melle, I.; Vaskinn, A.; Spigset, O.; Andreassen, O.A. Serum level of venlafaxine is associated with better memory in psychotic disorders. Schizophrenia Research 2015, 169(1-3): 386-392. doi: 10.1016/j.schres.2015.10.021.

93. Cardinal, R.N.; Savulich, G.; Mann, L.M.; Fernández-Egea, E. Association between antipsychotic/antidepressant drug treatments and hospital admissions in schizophrenia assessed using a mental health case register. NPJ Schizophrenia 2015, 21, 1:15035. doi: 10.1038/npjschz.2015 
94. Nikbakhat, M.R.; Arabzadeh, S.; Zeinoddini, A.; Khalili, Z.; Rezaei, F.; Mohammadinejad, P.; Ghaleiha, A.; Akhondzadeh, S. Duloxetine add-on to risperidone for treatment of negative symptoms in patients with stable schizophrenia: Randomized double-blind placebo-controlled study. Pharmacopsychiatry 2016, 49(4): 162-9. doi: 10.1055/s-0042-101557.

95. Mico, U.; Bruno, A.; Pandolfo, G.; Maria Romeo, V.; Mallamace, D.; D’Arrigo, C.; Muscatello, M. R. A. Duloxetine as adjunctive treatment to clozapine in patients with schizophrenia. International Clinical Psychopharmacology 2011, 26(6), 303310. doi: 10.1097/yic.0b013e32834bbc0d

96. Fava, M.; Papakostas, G.I.; Petersen, T.; Mahal, Y.; Quitkin, F.; Stewart, J.; McGrath, P. Switching to bupropion in fluoxetineresistant major depressive disorder. Annals of Clinical Psychiatry 2003, 15: 17-22.

97. Coryell W. Drug treatment of depression. in MSD Manual. Available: https://www.msdmanuals.com/professional/psychiatric-disorders/mood-disorders/drug-treatment-of-depression. Updated on Mar 2020

98. Patel, K.; Allen, S.; Haque, M.N.; Angelescu, I.; Baumeister, D.; Tracy, D.K. Bupropion: a systematic review and metaanalysis of effectiveness as an antidepressant. Therapeutic Advances in Psychopharmacology 2016, 6(2): 99-144. doi: $10.1177 / 2045125316629071$

99. Hamilton, M. A rating scale for depression. Journal of Neurology, Neurosurgery and Psychiatry 1960, 23(1): 56-62. doi: 10.1136/jnnp.23.1.56

100. Montgomery, S.A.; Asberg, M. A new depression scale designed to be sensitive to change. British Journal of Psychiatry 1979, 134: 382-389. doi: 10.1192/bjp.134.4.382.

101. Rush, A.J.; Giles, D.E.; Schlesser, M.A.; Fulton, C.L.; Weissenburger, J.; Burns, C. The Inventory for Depressive Symptomatology (IDS): preliminary findings. Psychiatry Research 1986, 18(1): 65-87. doi: 10.1016/0165-1781(86)90060-0.

102. Williams, J.B. A structured interview guide for the Hamilton Depression Rating Scale. Archives of General Psychiatry 1988, 45(8): 742-747. doi: 10.1001/archpsyc.1988.01800320058007

103. Brown, E.S.; Vornik, L.A.; Khan, D.A.; Rush, A.J. Bupropion in the treatment of outpatients with asthma and major depressive disorder. The International Journal of Psychiatry in Medicine 2007, 37(1): 23-28. doi: 10.2190/D235-2285-2121-6724.

104. Ferguson, J.; Cunningham, L.; Merideth, C.; Apter, J.; Feighner, J.; Ionescu-Pioggia, M.; Samara, B.; Johnston, J.A.; Ascher, J. Bupropion in tricyclic antidepressant nonresponders with unipolar major depressive disorder. Annals of Clinical Psychiatry 1994, 6(3): 153-60. doi: 10.3109/10401239409148997.

105. Gross, P.K.; Nourse, R.; Wasser, T.E.; Bukenya, D. Safety and efficacy of bupropion extended release in treating a community sample of Hispanic and african american adults with major depressive disorder: an open-label study. Primary Care Companion to The Journal of Clinical Psychiatry 2007, 9(2): 108-12. doi: 10.4088/pcc.v09n0204.

106. Walker, P.W.; Cole, J.O.; Gardner, E.A.; Hughes, A.R.; Johnston, J.A.; Batey, S.R.; Lineberry, C.G. Improvement in fluoxetineassociated sexual dysfunction in patients switched to bupropion. The Journal of Clinical Psychiatry 1993, 54(12): 459-465. PMID: 8276736.

107. Tomarken, A.J.; Dichter, G.S.; Freid, C.; Addington, S.; Shelton, R.C. Assessing the effects of bupropion SR on mood dimensions of depression. Journal of Affective Disorders 2004, 78(3): 235-241. doi: 10.1016/S0165-0327(02)00306-3

108. Hewett, K.; Chrzanowski, W.; Schmitz, M.; Savela, A.; Milanova, V.; Gee, M.; Krishen, A.; Millen, L.; Leary, M.O.; Modell, J. Eight-week, placebo-controlled, double-blind comparison of the antidepressant efficacy and tolerability of bupropion XR and venlafaxine XR. Journal of Psychopharmacology 2009, 23(5): 531-538. doi: 10.1177/0269881108089602.

109. Hewett, K.; Gee, M.D.; Krishen, A.; Wunderlich, H.P.; Le Clus, A.; Evoniuk, G.; Modell, J.G. Double-blind, placebocontrolled comparison of the antidepressant efficacy and tolerability of bupropion $\mathrm{XR}$ and venlafaxine XR. Journal of Psychopharmacology 2010, 24(8): 1209-1216. doi: 10.1177/0269881109106953 
110. Englisch, S.; Morgen, K.; Meyer-Lindenberg, A.; Zink, M. Risks and benefits of bupropion treatment in schizophrenia. Clinical Neuropharmacology 2013, 36(6): 203-215. doi: 10.1097/WNF.0b013e3182a8ea04

111. D’Agostino, A.; English, C.D.; Rey, J.A. Vortioxetine (Brintellix): a new serotonergic antidepressant. Drug Forecast PET 2015, 40(1): 36-40. PMID: 25628505

112. Rush, A.J.; Trivedi, M.H.; Wisniewski, S.R.; Stewart, J.W., Nierenberg, A.A.; Thase, M.E.; Ritz, L., Biggs, M.M., Warden D., Luther, J.F., Shores-Wilson, K., Niederehe, G., Fava, M. Bupropion-SR, sertraline, or venlafaxine-XR after failure of SSRIs for depression. The New England Journal of Medicine 2006, 354(12): 1231-1242. doi: 10.1056/NEJMoa052963.

113. Santarsieri, D.; Schwartz, T.L. Antidepressant efficacy and side-effect burden: a quick guide for clinicians. Drugs Context 2015; 4: 212-290. doi:10.7573/dic.212290

114. Purse, M. How reuptake inhibitor drugs work: in VeryWellMind. https://www.verywellmind.com/snris-and-ssnris-380183. February 62021.

115. Perry, L.A.; Ramson, D.; Stricklin, S. Mirtazapine adjunct for people with schizophrenia. Cochrane Database of Systematic Reviews 2018, 5(5). doi: 10.1002/14651858.CD011943.pub2

116. Lee, J.; Cho, S.J.; Lee, K.S.; Yook, K.; Choe, A.Y.; Lee, S.; Kim, B.; Kim, K.H.; Choi, T.K.; Lee, S.H. The tolerability of mirtazapine augmentation in schizophrenic patients treated with risperidone: a preliminary randomized placebo-controlled trial. Clinical Psychopharmacology and Neuroscience 2011, 9(2): 73-77. doi: 10.9758/cpn.2011.9.2.73

117. Abbasi, S.H.; Behpournia, H.; Ghoreshi, A.; Salehi, B.; Raznahan, M.; Rezazadeh, S.A.; Rezaei, F.; Akhondzadeh, S. The effect of mirtazapine add on therapy to risperidone in the treatment of schizophrenia: a double-blind randomized placebocontrolled trial. Schizophrenia Research 2010, 116(2-3): 101-6. doi: 10.1016/j.schres.2009.11.008.

118. Mathew, K.A. Efficacy of mirtazapine as adjunct therapy to antipsychotics in the treatment of chronic schizophrenia. Australian Medical Student Journal 2015, Available: http://www.amsj.org/archives/4308

119. Mutschler, J.; Rüsch, N.; Schönfelder, H.; Herwig, U.; Brühl, A.B.; Grosshans, M.; Rössler, W.; Russmann, H. Agomelatine for depression in schizophrenia: A Case-Series. Psychopharmacology Bulletin 2012, 45(1): 35-43. PMID: 27738367

120. Singh, S.; Singh, V.; Kar, N.; Chan, K. Efficacy of antidepressants in treating the negative symptoms of chronic schizophrenia: Meta-analysis. British Journal of Psychiatry 2015, 197(3), 174-179. doi:10.1192/bjp.bp.109.067710.

121. Englisch, S.; Jung, H.S.; Lewien, A.; Becker, A.; Nowak, U.; Braun, H.; Thiem, J.; Eisenacher, S.; Meyer-Lindenberg, A.; Zink, M. Agomelatine for the Treatment of Major Depressive Episodes in Schizophrenia-Spectrum Disorders: An OpenProspective Proof-of-Concept Study. Journal of Clinical Psychopharmacology 2016, 36(6): 597-607. doi: 10.1097/JCP.0000000000000587.

122. De Berardis, D.; Fornaro, M.; Serroni, N.; Campanella, D.; Rapini, G.; Olivieri, L.; Srinivasan, V.; Iasevoli, F.; Tomasetti, C.; De Bartolomeis, A.; Valchera, A.; Perna, G.; Mazza, M.; Di Nicola, M.; Martinotti, G.; Di Giannantonio, M. Agomelatine beyond Borders: Current Evidences of Its Efficacy in Disorders Other than Major Depression. International Journal of Molecular Sciences 2015, 16, 1111-1130. https://doi.org/10.3390/ijms16011111.

123. Mutschler, J.; Rüsch, N.; Schönfelder, H.; Herwig, U.; Brühl, B.A.; Grosshans, M.; Rössler, W. Agomelatine for Depression in Schizophrenia: A Case-Series. Psychopharmacology Bulletin 2012; 45(1): 35-43

124. Stuhec, M.; Oravecz, R. Moclobemide as add-on therapy to agomelatine in a patient with treatment-resistant major depressive disorder: a psychopharmacological case. Wien Klin Wochenschr 2016; 128(7-8): 295-298. doi: 10.1007/s00508-0150861-0.]

125. Shiloh, R.; Zemishlany, Z.; Aizenberg, D.; Valevski, A.; Bodinger, L.; Munitz, H.; Weizman, A. Mianserin or placebo as adjuncts to typical antipsychotics in resistant schizophrenia. International Clinical Psychopharmacology 2002, 17(2): 59-64. doi: 10.1097/00004850-200203000-00003.

126. Cowen, P.J. Psychopharmacology. In Comprehensive Clinical Psychology 1998. doi: 10.1016/B0080-4270(73)00248-0 
127. Verbenko V.A., Aristov M.A. Pharmacological therapy of schizophrenia (modern view). Taurida Journal of Psychiatry 2015, $70(1): 5-14$.

128. Danilov, D.S.; Magomedova, D.O.; Matsneva, M.E. The rationale for antidepressants in the treatment of schizophrenia: A modern view on the problem in the context of evidence-based medicine. Neurology, Neuropsychiatry, Psychosomatics 2016, 8(1): 71-81. doi: 10.14412/2074-2711-2016-1-71-81

129. Millan, M.J.; Agid, Y.; Brüne, M.; Bullmore, E.T.; Carter, C.S.; Clayton, N.S.; Connor, R.; Davis, S.; Deakin, B.; DeRubeis, R.J.; Dubois, B.; Geyer, M.F.; Goodwin, G.M.; Gorwood, P.; Jay, T.M.; Joëls, M.; Mansuy, I.M.; Meyer-Lindenberg, A.; Murphy, D.; Rolls, E.; Saletu, B.; Spedding, M.; Sweeney, J.; Whittington, M.; Young, L.J. Cognitive dysfunction in psychiatric disorders: characteristics, causes and the quest for improved therapy. Nature Reviews Drug Discovery 2012, 11(2): 141-168. doi: $10.1038 / \mathrm{nrd} 3628$

130. Allain, H.; Lieury, A.; Brunet-Bourgin, F.; Mirabaud, C.; Trebon, P.; Le Coz, F.; Gandon, J.M. Antidepressants and cognition: comparative effects of moclobemide, viloxazine and maprotiline. Psychopharmacology 1992, 106: 56-61. doi: 10.1007/BF02246237

131. Chertkow, Y.; Weinreb, O.; Youdim, M.B.; Silver, H. Molecular mechanisms underlying synergistic effects of SSRIantipsychotic augmentation in treatment of negative symptoms in schizophrenia. Journal of Neural Transmission 2009, 116(11): 1529-1541. doi: 10.1007/s00702-009-0255-4

132. Harrison, P. Antidepressants have a role to play in schizophrenia. American Journal of Psychiatry 2016, Available: https://www.medscape.com/viewarticle/865418

133. Wang, P.; Si, T. Use of antipsychotics in the treatment of depressive disorders. Shanghai Arch Psychiatry 2013; 25(3): 134-140. doi:10.3969/j.issn.1002-0829.2013.03.002

134. Earley, W.; Guo, H.; Daniel, D.; Nasrallah, H.; Durgam, S.; Zhong, Y.; Patel, M.; Barabássy, Á.; Szatmári, B.; Németh, G. Efficacy of cariprazine on negative symptoms in patients with acute schizophrenia: A post hoc analysis of pooled data. Schizophr Res 2019; 204:282-288. doi: 10.1016/j.schres.2018.08.020

135. Andrusenko, M.P.; Morozova, M.A. A combination of antidepressants and neuroleptics in the treatment of affective disorders and schizophrenia: indications, side effects and complications. Journal of Neurology and Psychiatry named after S.S. Korsakova 2000, 100(11): 60-65. PMID: 11247192

136. Dunner, D.L.; Amsterdam, J.D.; Shelton, R.C.; Loebel, A.; Romano, S.J. Efficacy and tolerability of adjunctive ziprasidone in treatment-resistant depression: a randomized, open-label, pilot study. J Clin Psychiatry 2007; 68(7):1071-1077

137. Barbee, J.G.; Conrad, E.J.; Jamhour, N.J. The effectiveness of olanzapine, risperidone, quetiapine, and ziprasidone as augmentation agents in treatment-resistant major depressive disorder. J Clin Psychiatry 2004; 65(7): $975-981$.

138. Usov, G.M. Second generation antipsychotics in acute and long-term treatment of schizophrenia: a critical review of scientific data. Therapy of Mental Disorders 2020, 4: 28-35. doi: 10.21265/PSYPH.2020.94.92.004

139. Štuhec, M. Solifenacin-induced delirium and hallucinations. General Hospital Psychiatry 2013, 35(6): 682.e3-4. doi: 10.1016/j.genhosppsych.2013.06.002.

140. Štuhec, M.; Potočin, I.; Stepan, D.; Ušaj, L.; Petek, S.M.; Beović, B. Potential drug interactions with antibacterials in longterm care facilities analyzed by two interaction checkers. International Journal of Clinical Pharmacy 2019, 41(4):932-938. doi: 10.1007/s11096-019-00855-x. 